\title{
Public Health Guidance and Research Strategies to Combat the Next COVID Pandemic
}

\author{
Reed Cooper ${ }^{1}$ and Mark Crowder* \\ 1Joel Barlow High School, Redding, CT, USA \\ \#Advisor
}

\section{ABSTRACT}

COVID-19 has severely disrupted the lives of many with respect to health, economic security, and social behaviors. By analyzing the U.S. response to COVID-19, strategies for dealing with the next pandemic can be established. Analyses on the politicization of science reveal the ineffectiveness of political commentary in overcoming the COVID-19 pandemic, as seen through heterogenous behavioral patterns throughout the U.S. in regard to pandemic prevention measures, such as social distancing. Economic data reveal the importance of financially prioritizing small businesses over large ones and how to ensure individuals are motivated to return to work. The mask mandate was not widely respected throughout the U.S. and was a primary reason for the pandemic's prolonged effects. Due to a lack of trust in the leading health experts, non-pharmaceutical prevention methods were not as effective as they could have been. By analyzing vaccine data, it is clear that pharmaceuticals can and should be developed prior to the next pandemic. Based on the principle of cross-immunity, vaccines that incorporate genomic similarities between virus groups can be researched and administered, which will theoretically reduce the immune system's reaction to the next novel virus. Overall, the U.S. response to the COVID-19 pandemic had effective and ineffective components. By studying public health procedures and results from this pandemic, recommendations can be made to improve the response to the next pandemic.

\section{General COVID-19 Information}

\section{Type of Disease}

COVID-19 is a disease caused by the virus severe acute respiratory syndrome coronavirus 2 (SARS-CoV-2). This virus primarily affects the respiratory system, blood vessels, muscles, airways, and lungs and therefore can reduce the amount of oxygen that is supplied to the body. Ultimately, the body can fail to clear waste gases, such as carbon dioxide, which can exacerbate COVID-19 infection (Respiratory System, 2020).

\section{Transmission}

COVID-19 is transmitted primarily through respiratory droplets, which are spread when someone sneezes, coughs, or talks. Infected individuals can easily transmit the virus to others close by (approximately 1 meter or less) if no preventative measures are taken. Infected respiratory droplets do not need to land in the nose or mouth of another individual to spread COVID-19, but rather, they can land on hands or other surfaces and infect other individuals through the touching of one's face (COVID-19 Overview and Infection Prevention, 2021). 


\section{Symptoms}

- Fever

- Chills

- Cough

- Fatigue

- Muscle or body aches

- Headache

- New loss of taste or smell

- Sore throat

- Congestion or runny nose

- Nausea or vomiting

- Diarrhea

- Dyspnea

- Sputum

All symptoms associated with COVID-19 infection are attributed to the immune system's unique response to the SARS-CoV-2 virus (Billingsley et al., 2021). When an unvaccinated individual comes in contact with COVID-19, their immune system responds by developing antibodies and white blood cells to both attack and remember the virus, which makes it easier to recognize and suppress the virus in the future. The adaptive immune system also creates B cells, which are white blood cells made by bone marrow. These cells make antibodies that are specific to the virus and that bind to the virus so that other immune cells can recognize it. The adaptive immune system's creation of white blood cells, antibodies, B cells, and more can cause symptoms like fatigue, muscle aches, and fevers (Billingsley et al., 2021).

As a respiratory disease, COVID-19 mainly affects the lungs and the surrounding tissue. The disease can cause alveolar damage, edema, and interstitial pneumonia with a geographically heterogeneous pattern, mostly affecting the central part of the lungs (Aguiar et al., 2020). The heart is indirectly impacted by the SARS-CoV-2 virus through the blockage of blood vessels, which can damage the coagulation system, a bodily system composed of cells, proteins and processes that mediate blood clotting (Topol, 2020). As a result, blood clots can form and block organs from receiving oxygen, potentially leading to strokes (Topol, 2020). COVID-19 can lead to myocarditis (inflammation of the heart), necrosis of its cells, mimicking of a heart attack, arrhythmias, and acute or protracted heart failure (muscle dysfunction). These complications, which at times are the only features of COVID-19 clinical presentation, have occurred even in cases with mild symptoms and in people who did not experience any symptoms (Topol, 2020).

There is evidence that supports long-term damage from COVID-19 infection, as seen in the diagnosis of long COVID. Long COVID is a condition where individuals experience the symptoms of COVID-19 months after their initial infection. Lingering medical conditions include sequelae in the respiratory and nervous system, as well as neurocognitive disorders, mental health disorders, metabolic disorders, cardiovascular disorders, gastrointestinal disorders, malaise, fatigue, musculoskeletal pain and anaemia (Al-aly et al., 2021). Some consequences are a result of inflammation provoked by the virus, while others are linked to life changes that might accompany the disease, such as reduced physical activity, changes in diet, and other alterations that can be attributed to quarantine mandates (Alaly et al., 2021).

Long-term multiorgan effects are also indicative of permanent damage from COVID-19 infection. Multisystem inflammatory syndrome is a symptom of multiorgan effects and occurs when parts of the body become swollen after serious cases of COVID-19 (Al-aly et al., 2021).

Other important long COVID symptoms include unstable blood regulation, which can cause dizziness, a fastbeating heart (resulting from neurological disorders), muscle pain, loss of taste/smell, depression, anxiety, and irreversible destruction of lung tissue (COVID 'Long haulers', 2021). 


\title{
Analyzing the U.S. COVID-19 Pandemic Response
}

\author{
The Politicization of Science
}

News coverage and political opinion played a significant role during the COVID-19 pandemic and had the ultimate effect of politicizing science. This led to a national gridlock between scientific advancement and political controversy and influenced public attitudes in a way that exacerbated partisan divides (Hart et al., 2020). Despite widespread public agreement on certain pandemic preventative measures, such as restrictions on international travel to the U.S. and limited in-person education models (Van Green et al., 2020). Americans have been politically divided in their perceptions of the government's response and universal trust in scientists. For instance, $83 \%$ of Republicans rated President Trump's response to COVID-19 as good or excellent, whereas only 18\% of Democrats did so (Van Green et al., 2020). Democrats had greater confidence than Republicans that medical scientists would act in the best interests of the public in 2019. As of April 2020, Democratic support for medical science continued to grow while Republican support remained stagnant (Funk et al., 2020). Differences in partisan perceptions of COVID-19 can be due to differences in ideology about the role of government, including government-issued public health guidance. President Trump and leading conservative political commentators frequently referred to COVID-19 as a "hoax" and have been dismissive of the risks the virus posed. This political commentary on the virus affected political populations within the US. These differences in political thought correlate with public behavior. GPS data collected from smartphones reveals that more Republican areas exhibited less social distancing than Democratic areas within the U.S. (Allcott et al., 2020). These behavioral differences pose serious health risks, as minimal social distancing during the COVID-19 pandemic is non-ideal and leads to greater outbreaks in those regions. Through the politicization of science, individuals throughout the U.S. have adopted heterogeneous behavioral responses to the virus. These behaviors account, in part, for the prolonged duration of the pandemic and can influence later policy regarding behavioral homogeneity during the next pandemic. Stricter restrictions must be implemented to ensure that all individuals, regardless of political affiliation, are taking the same preventative measures to the same degree. When the next pandemic occurs, the federal government should take complete charge in creating and overseeing preventative measures. These measures include wearing a mask in all public spaces, maintaining a distance of 6 feet from others, reducing the number of crowds in public spaces, ensuring the ventilation of public facilities, and offering frequent sanitization opportunities (How to Protect Yourself, 2021). Businesses that do not uphold these regulations must be subject to various fines, which will then be sourced for scientific research. Safety is a priority during any pandemic, and if heterogenous preventative measures are utilized throughout the US, individuals will only suffer in the long run.

\section{Economic Depression}

The COVID-19 pandemic not only raised severe health concerns, but economic ones too. In a study conducted between March 28 and April 4, 2020, 5,800 small businesses that are a part of Alignable, a network of 4.6 million small businesses, were surveyed for the impacts of COVID-19. It was determined that $90 \%$ of these businesses believed the pandemic or COVID-19 related disruptions would end by January 2021 (Bartik et al., 2020). Although the effects of the pandemic on the economy were much more prolonged, this can help explain the fact that $35 \%$ of these businesses did not apply for a CARES Act loan, claiming that they "simply did not need the cash" (Bartik et al., 2020). The closing of small businesses was primarily responsible for the extensive occupational separations that took place. When surveyed, businesses with 50 or more employees were more optimistic about their survival than those with fewer than 50 employees (Bartik et al., 2020). Clearly, financial loans were not at the root of an economic solution, and ultimately, the failure of the CARES Act to examine what type of relief would best stimulate the economy was a reason why the pandemic had such disastrous economic effects. Not only should these relief resources be more extensive, but financial 
assistance should also be targeted disproportionately at smaller businesses, those with fewer than 50 employees. Building off of the reported optimism of small and large businesses, this financial modification would promote emotional and economic security by minimizing the closure of small businesses.

In May of 2020, approximately 9.74 million people could not find work in the U.S. because of the COVID19 pandemic. For reference, in July of 2021, that number fell to approximately 1.58 million (Supplemental Data Measuring the Effects, 2021). Despite the reduction in unemployment numbers from May of 2020 to July of 2021 , there are still concerns regarding the desire to work. 633,000 of the 1.58 million individuals who are not in the workforce due to COVID-19 complications, roughly 40\%, reported as "not wanting a job" (Supplemental Data Measuring the Effects, 2021). This is a major issue because economic hardship will remain if individuals who have lost their jobs do not return to work.

After taking on additional responsibilities during the COVID-19 pandemic, many women left their jobs and feel incapable of returning to work (Jackson, 2021). Instead of simply increasing job availability and trust within the workplace, an emphasis on subsidising daycare and other familial needs must be placed. These funds can be taken from CARES Act loans and will have tremendous restorative power with respect to the quantity of working individuals.

\section{The Mask Mandate}

At the start of any pandemic, non-pharmaceutical intervention methods must be utilized in order to quickly and effectively flatten the infection curve. Mandatory mask mandates were and are necessary in the fight against any deadly virus. Masks limit turbulent gas cloud formation and respiratory pathogen emission (Bourouiba, 2020). Research shows that masks accomplish this by blocking and/or redirecting rapid turbulent jets, streams of air that carry respiratory droplets, emitted when coughing or sneezing (Tang et al., 2009). Overall, masks limit infectious airflow, which is necessary in any public space during a pandemic. The mask material itself can filter infectious particles such as aerosols or droplets to various degrees (Van der Sande et al., 2008). In the event of asymptomatic infection, mask mandates are necessary as a precaution, especially if the asymptomatic individual is unaware of their viral infection. By restricting the movement and spread of potentially infectious particles, masks prove to be one of the most effective non-pharmaceutical intervention methods available.

While masks are highly effective in reducing viral transmission, mask mandate policy within the U.S. was largely heterogeneous, often falling under states' responsibilities (Althouse et al., 2020). Nonuniform mask policy is highly ineffective in overcoming any pandemic, as the reduction in viral transmission is only successful when all individuals in a particular region abide by the same standards. In the early stages of the COVID-19 pandemic, Dr. Anthony Fauci advocated for facial coverings as an effective non-pharmaceutical intervention method. However, he received much lashback for advocating for a mandate with little research and data as it pertained to COVID-19 (Woodruff et al., 2020). At the start of any pandemic, it is best to rely on data from former pandemics and utilize previously completed research to inform our current decisions. Dr. Fauci's support for masks was not ill-founded, but rather grounded in extensive research completed on numerous pandemics throughout the last century. Pandemic influenza (H1N1), which emerged in Mexico in early 2009 rapidly spread worldwide (Xu et al., 2010). Researchers tested the efficacy of masks in preventing viral transmission by having participants cough five times onto a Petri dish containing a viral transport medium held $20 \mathrm{~cm}$ in front of their mouth. The experiment was repeated with subjects wearing a surgical mask and wearing an N95 respirator. While influenza virus could be detected in all nine volunteers without a mask, no influenza virus could be detected on the Petri dish specimens when participants wore either type of face mask (Johnson et al., 2009). It is important to note that the type of mask utilized, certified medical masks that meet government standards, uncertified medical masks subject to FDA jurisdiction, and homemade masks, makes an impact on the transmission of the virus (Li et al., 2020).

Thus, while research on new pandemics may be limited, logical decisions regarding the limiting of viral transmission can be made by analyzing research from prior pandemics. Masks are not only advantageous for limiting the spread of COVID-19; they're necessary for any health crisis. The global health leaders during any pandemic must 
remain transparent with the population, even if that entails advocating for a safety precaution that has not been widely tested in the context of a current pandemic.

\title{
Vaccine Study
}

The US, as well as other countries, was quick to fund vaccine research, which is essential in defeating any pandemic. Ultimately, this research was enabled by decades of long-term investments by the federal government, followed by additional federal investment in the development of the COVID-19 vaccines themselves. Around \$900 million was invested in preclinical development and clinical trials for the vaccines. Additionally, the government ensured vaccines were readily available to citizens, which included advertisement and contracts with various pharmaceutical companies (Frank et al., 2021). The government supported additional preclinical studies, absorbed the bulk of human testing costs and risk through a set of contracts that paid for the various phases of vaccine development and manufacturing, and reduced manufacturing risk by underwriting capacity investments (Frank et al., 2021).

The success of the COVID-19 vaccine development project reflects the determination of the government to ensure public safety during a fatal health crisis. Through the expansive mobilization of public resources to work with industry to produce products with enormous health, social, and economic benefits, the federal government allowed for the swift development of effective and safe vaccines.

Various vaccines are effective in reducing the threat of COVID-19, but for purposes of this paper, only mRNA vaccines will be discussed. The Moderna and Pfizer mRNA vaccines are both widely used and effective. In COVID-19 mRNA vaccines, the mRNA molecule is encapsulated in lipid nanoparticles, which minimize degradation of the mRNA and assist in endocellular penetration (Zhang et al., 2020). After the encapsulated mRNA enters the muscle deltoid cells and passes into the cytosol, the ribosomes perform cellular translation, producing the spike protein, which when released into the circulation stimulates the immune response. The SARS-CoV-2 spike proteins allow the virus to penetrate host cells and are also the target of the neutralizing antibodies the body produces in order to eliminate the virus (Vitiello et al., 2021). By predisposing cells to the SARS-CoV-2 spike protein, mRNA vaccines allow the body to preemptively produce antibodies that will eliminate the virus in the case of infection.

While vaccine development was rapid, there are still ways to improve moving forward. For instance, little instruction was given to those who do not receive the vaccine (Yelin et al., 2021). This target population of people who are potentially incapable of building COVID-19 immunity includes people with immunodeficiency viruses, people currently taking immunosuppressant drugs, older individuals, children below the age of 12 , and people who do not want to get vaccinated (Information for Special Populations, 2021). All individuals who do not receive a vaccine simply must take extra precautions when interacting with others. While it may be hard to enforce, strict mandates must be implemented for these individuals to continue abiding by the mask mandate, to wash their hands frequently, to social distance, and to minimize their interactions with others in society. Proof of vaccination, or lack thereof, can be used to monitor these individuals and ensure the safety of the general population. Moving forward, children below the age of 12 should be included in vaccine trials. With the COVID-19 vaccine rollouts, this population has been pushed back and neglected. It is not only logical to diversify the vaccine trial populations, but also a way to reassure parents and health workers that it is safe to distribute these vaccines to children. Since the onset of the pandemic, approximately 4.2 million children have been infected with COVID-19 (Children and COVID-19, 2021), and children have not only suffered physically, but also with respect to their education and their mental and emotional health. The greatly diminished access to critical medical services, such as COVID-19 vaccines, by children has extended this suffering. In order to ensure the effectiveness of the COVID-19 vaccines, diverse populations must be used.

\section{Cross-Immunity as a Means of Mitigating Immune System Overreaction}

\author{
Asymptomatic Infection
}


With respect to COVID-19, asymptomatic infections refers to the detection of nucleic acid of SARS-CoV-2 in patient samples by reverse transcriptase-polymerase chain reaction, but have no typical clinical symptoms or signs and no apparent abnormalities in images, including lung computed tomography (Gao et al., 2021). It is important to understand that while an asymptomatic individual may not suffer any health issues from COVID-19, they still play a role in the transmission of the virus. Asymptomatic responses to COVID-19 are completely based on the strength of the infected individual's immune system response. Those with severe COVID-19 symptoms have immune systems that overreacted to the foreign virus while those with no symptoms have immune systems that did not recognize the virus as a threat.

\section{Causes of Asymptomatic Infection to COVID-19}

One prominent theory regarding asymptomatic infection is that these individuals already possess the antibodies needed to defeat the SARS-CoV-2 virus. It is possible that such individuals were exposed to other similar viruses earlier in their lifetimes, meaning their bodies may have already built an immune response to a specific protein that is utilized on the SARS-CoV-2 virus. It is believed that the stronger the exposure to previous coronavirus infections, the lower the chances that hospitalization was required upon SARS-CoV-2 infection (Kashir et al., 2021). Previous coronavirus outbreaks have included severe respiratory syndrome (SARS) caused by SARS-CoV, and Middle East respiratory syndrome (MERS) caused by MERS-CoV. SARS-CoV, MERS-CoV, and SARS-CoV-2 share significant sequence homology and antigenic epitopes capable of inducing an adaptive immune response (Yaqinuddin, 2020). All coronaviruses consist of transmembrane trimeric spike glycoproteins, membrane glycoproteins, and transmembrane envelope proteins (Kashir et al., 2021). Due to the overwhelming similarities between coronaviruses, previous exposure to SARS or MERS may have been sufficient enough for a patient to build effective antibodies for COVID-19. Furthermore, a study published in Science (Shrock et al., 2020) examined 232 COVID-19 patients and 190 pre-COVID-19 era controls and found that more antibodies relating to various rhinoviruses, enteroviruses, and influenza were observed in COVID-19 patients with weak immune system responses, while those with stronger immune system responses possessed fewer antibodies related to other viruses (Shrock et al., 2020). This proves that immunity to asymptomatic responses to COVID-19 do not only have to come from similar viruses, coronaviruses, but can also come from others with similar genomes.

\section{Utilizing Cross-Immunity to Limit Immune System Overreaction}

Cross-immunity to novel viruses should be induced in patients in order to elicit an asymptomatic reaction to future infection with similar genomes. Prophylactic or therapeutic intervention is needed at the earliest. Therefore, drug/vaccine repurposing should be explored with the intention of identifying potential target antigen sequences of previously known coronavirus strains to come up with suitable vaccines for novel virus strains (Kaur et al., 2021). This research must also be extended to other viruses in order to be effective.

There are many genomic similarities between distinct coronavirus strains, such as the genetic organization for the coding region encoding for a canonical set of genes in the order $5^{\prime}$ end- open reading frame (ORF) $1 \mathrm{a} / \mathrm{b}$ replicase, spike, envelope, membrane, and nucleocapsid-3' end (Sasseville et al., 2002). Due to the fact that distinct coronavirus strains possess genomic similarities, it is possible to develop vaccines for a novel coronavirus before much research has been conducted on the new virus strain itself. This research is also applicable to other viruses, such as rhinoviruses and noroviruses. By establishing genomic similarities between various strains within each virus group, vaccines can be prepared before the start of the next pandemic. Despite the inability to know with certainty what type of virus the next pandemic will be a result of, conducting research on these genomic similarities will allow vaccination to occur much more easily and quickly during the next pandemic. More research on the genomic composition of 
various terminals and protein-producing genes in various viruses is needed in order to develop effective pharmaceutical intervention methods.

If these general virus vaccines are administered before the start of the next pandemic, more individuals will most likely have less severe reactions to the new virus (Kashir et al., 2021). This is because if individuals are exposed to genome sequences present in multiple viruses, they will most likely produce and remember the immunoglobulins necessary to defeat the next pandemic-level virus (Kashir et al., 2021). Cross-immunity is the future of pandemic vaccination because it ensures the safety of the general population and is extremely effective. By building the antibodies necessary to defeat the next major virus in a controlled setting, people's immune systems will not overreact when infected with the next virus, and ultimately, the symptoms of such an infection will be mitigated.

\section{Conclusion}

Come the next global pandemic, many new and harsher policies need to be adopted in order to ensure the safety of the general population. Recovering from the next pandemic should not fall upon the federal, state, and local governments with respect to policy creation. The CDC and WHO, led by medical experts, must collaboratively create public mandates to be enforced by the government. Political commentary on certain preventative measures, such as mask mandates or quarantines, will only serve to divide the U.S. population politically and will cause the country to experience another gridlock between scientific advancement and political controversy. Ultimately, more power needs to be given to the leading medical experts, and all governments should enforce the mandates from the CDC and WHO in order to ensure behavioral homogeneity throughout the United States. Individuals and businesses that do not comply with CDC and WHO policies should be subject to various fines, which will then be sourced for scientific research.

In the future, financial loans should be primarily reserved for small businesses, businesses with fewer than 50 employees. This is due to the fact that small businesses were less optimistic about their survival during the COVID19 pandemic than large businesses, businesses with more than 50 employees (Bartik et al., 2020).

When it comes to preventative measures such as mask mandates, leading health experts should continue to rely on data from former pandemics to influence current decisions. Regardless of the classification of the next pandemic-level virus, mask mandates should be utilized and enforced. Further changes in mask policy may be made after subsequent research. Masks are not only advantageous for limiting the spread of COVID-19; they're necessary for any health crisis. The global health leaders during any pandemic must remain transparent with the population, even if that entails advocating for a safety precaution that has not been widely tested in the context of a current pandemic.

Just as with the COVID-19 pandemic, the U.S. should make vaccine research a priority during the next pandemic. However, instructions for individuals who either cannot or choose not to receive the vaccine should be bolstered in the future. Quarantining, mask mandates, and frequent sanitization should be enforced for people with immunodeficiency viruses, people currently taking immunosuppressant drugs, older individuals, children below the age of 12, and people who do not want to get vaccinated. Proof of vaccination, or lack thereof, can be used to monitor these individuals and ensure the safety of the general population. Moving forward, children below the age of 12 should be included in vaccine trials.

Considering the presence of asymptomatic infection in any given population with any virus, it is important that enough viral tests are accessible and administered to the general population on a regular basis. Money that would typically go towards legislation such as the CARES Act, which would need to be restricted, can be put towards the creation of viral antibody tests. Individuals who regularly attend work or school must be subject to regular antibody testing in order for health organizations to better observe infection patterns and to especially monitor those with asymptomatic infections, who would most likely otherwise go untested.

Cross-immunity should be used to reduce the likelihood of severe/fatal infection with the next virus. To do this, drug/vaccine repurposing should be explored with the intention of identifying potential target antigen sequences of previously known coronavirus strains to come up with suitable vaccines for novel virus strains. This research must also be extended to other viruses, like rhinoviruses and noroviruses, in order to be effective. By establishing genomic 
similarities between various strains within each virus group, vaccines can be prepared before the start of the next pandemic, thus potentially weakening the immune system's reaction to infection of the next pandemic-level virus. Ultimately, cross-immunity is a viable method for mitigating the health risks of the next pandemic, but will only be effective if the general population abides by the mandates created by the CDC. Just as scientists will do their part to create safe and effective vaccines, ideally before the next pandemic, regular individuals must do their part to wear masks, trust the leading health experts and monitor their symptoms. Similarly, the government must also do its part in sensibly allocating financial loans to small businesses, provide regular testing opportunities to citizens, and avoid commentary on scientists' recommendations.

\section{Acknowledgments}

I would like to thank Dr. Reto Asmis for lecturing me on virology, epidemiology, and immunology as well as Dr. Mark Crowder for helping me develop and edit my research paper. Both of these individuals made my experience unique and furthered my interest in science research.

\section{References}

1. Aguiar, D., Lobrinus, J. A., Schibler, M., Fracasso, T., \& Lardi, C. (2020). Inside the lungs of covid-19 disease. International Journal of Legal Medicine, 134(4), 1271-1274. https://doi.org/10.1007/s00414-02002318-9

2. Al-aly, Z., Xie, Y., \& Bowe, B. (2021). High-dimensional characterization of post-acute sequelae of covid19. Nature, 594(7862), 259-264. https://doi.org/10.1038/s41586-021-03553-9

3. Allcott, H., Boxell, L., Conway, J., Gentzkow, M., Thaler, M., \& Yang, D. (2020). Polarization and public health: Partisan differences in social distancing during the coronavirus pandemic. Journal of Public Economics, 191, 104254. https://doi.org/10.1016/j.jpubeco.2020.104254

4. Althouse, B. M., Wallace, B., Case, B., Scarpino, S. V., Berdahl, A. M., White, E. R., \& Hébert-dufresne, L. (2020). The unintended consequences of inconsistent pandemic control policies. Science. https://doi.org/10.1101/2020.08.21.20179473

5. Bartik, A. W., Bertrand, M., Cullen, Z., Glaeser, E. L., Luca, M., \& Stanton, C. (2020). The impact of covid-19 on small business outcomes and expectations. Proceedings of the National Academy of Sciences, 117(30), 17656-17666. https://doi.org/10.1073/pnas.2006991117

6. Billingsley, A., PharmD. (2020, October 9). How does the immune system fight COVID-19? GoodRx. Retrieved August 19, 2021, from https://www.goodrx.com/blog/how-the-immune-system-fights-covid-19/

7. Bourouiba, L. (2020). Turbulent gas clouds and respiratory pathogen emissions. JAMA. https://doi.org/10.1001/jama.2020.4756

8. Children and covid-19: State-level data report. (2021, August 23). American Academy of Pediatrics. Retrieved August 19, 2021, from https:/www.aap.org/en/pages/2019-novel-coronavirus-covid-19infections/children-and-covid-19-state-level-data-report/

9. COVID-19 overview and infection prevention and control priorities in non-US healthcare settings. (2021, February 26). Centers for Disease Control and Prevention. Retrieved August 19, 2021, from https://www.cdc.gov/coronavirus/2019-ncov/hcp/non-us-settings/overview/index.html\#background

10. COVID 'Long haulers': Long-Term effects of COVID-19. (2021, April 1). Johns Hopkins Medicine. Retrieved August 24, 2021, from https://www.hopkinsmedicine.org/health/conditions-anddiseases/coronavirus/covid-long-haulers-long-term-effects-of-covid19 
11. Frank, R. G., Dach, L., \& Lurie, N. (2021, May 14). It was the government that produced covid-19 vaccine success. Health Affairs. Retrieved August 19, 2021, from https://www.healthaffairs.org/do/10.1377/hblog20210512.191448/full/

12. Funk, C., Kennedy, B., \& Johnson, C. (2020, May 21). Trust in medical scientists has grown in U.S., but mainly among democrats. Pew Research Center. Retrieved August 19, 2021, from https://www.pewresearch.org/science/2020/05/21/trust-in-medical-scientists-has-grown-in-u-s-but-mainlyamong-democrats/

13. Gao, Z., Xu, Y., Sun, C., Wang, X., Guo, Y., Qiu, S., \& Ma, K. (2021). A systematic review of asymptomatic infections with covid-19. Journal of Microbiology, Immunology and Infection, 54(1), 12-16. https://doi.org/10.1016/j.jmii.2020.05.001

14. Hart, P. S., Chinn, S., \& Soroka, S. (2020). Politicization and polarization in covid-19 news coverage. Science Communication, 42(5), 679-697. https://doi.org/10.1177/1075547020950735

15. How to protect yourself \& others. (2021, August 13). Centers for Disease Control and Prevention. Retrieved August 19, 2021, from https:/www.cdc.gov/coronavirus/2019-ncov/prevent-gettingsick/prevention.html

16. Information for special populations and the COVID-19 vaccine. (2021, August 18). Yale Health. Retrieved August 24, 2021, from https://yalehealth.yale.edu/yale-covid-19-vaccine-program/information-specialpopulations-and-covid-19-vaccine

17. Jackson, L. (2021, August 6). Why aren't people going back to their jobs? The New York Times. Retrieved August 19, 2021, from https://www.nytimes.com/2021/08/06/podcasts/jobs-report-labor-shortage.html

18. Johnson, D., Druce, J., Birch, C., \& Grayson, M. (2009). A quantitative assessment of the efficacy of surgical and $\mathrm{n} 95$ masks to filter influenza virus in patients with acute influenza infection. Clinical Infectious Diseases, 49(2), 275-277. https://doi.org/10.1086/600041

19. Kashir, J., Alkattan, K., \& Yaqinuddin, A. (2021). COVID-19: Cross-immunity of viral epitopes may influence severity of infection and immune response. Signal Transduction and Targeted Therapy, 6(1). https://doi.org/10.1038/s41392-021-00490-x

20. Kaur, N., Singh, R., Dar, Z., Bijarnia, R. K., Dhingra, N., \& Kaur, T. (2021). Genetic comparison among various coronavirus strains for the identification of potential vaccine targets of sars-cov2. Infection, Genetics and Evolution, 89, 104490. https://doi.org/10.1016/j.meegid.2020.104490

21. Li, T., Liu, Y., Li, M., Qian, X., \& Dai, S. Y. (2020). Mask or no mask for covid-19: A public health and market study. PLoS ONE, 15(8), e0237691. https://doi.org/10.1371/journal.pone.0237691

22. Respiratory system. (2020, January 24). Cleveland Clinic. Retrieved August 19, 2021, from https://my.clevelandclinic.org/health/articles/21205-respiratory-system

23. Sasseville, A. M.-J., Boutin, M., Gélinas, A.-M., \& Dea, S. (2002). Sequence of the 3'-terminal end (8.1 kb) of the genome of porcine haemagglutinating encephalomyelitis virus: Comparison with other haemagglutinating coronaviruses. Journal of General Virology, 83(10), 2411-2416. https://doi.org/10.1099/0022-1317-83-10-2411

24. Shrock, E., Fujimura, E., Kula, T., Timms, R. T., Lee, I.-H., Leng, Y., Robinson, M. L., Sie, B. M., Li, M. Z., Chen, Y., Logue, J., Zuiani, A., Mcculloch, D., Lelis, F. J. N., Henson, S., Monaco, D. R., Travers, M., Habibi, S., Clarke, W. A., . . Elledge, S. J. (2020). Viral epitope profiling of covid-19 patients reveals cross-reactivity and correlates of severity. Science, 370(6520), eabd4250. https://doi.org/10.1126/science.abd4250

25. Supplemental data measuring the effects of the coronavirus (COVID-19) pandemic on the labor market. (2021, August 19). U.S. Bureau of Labor Statistics. Retrieved August 19, 2021, from https://www.bls.gov/cps/effects-of-the-coronavirus-covid-19-pandemic.htm\#data 
26. Tang, J. W., Liebner, T. J., Craven, B. A., \& Settles, G. S. (2009). A schlieren optical study of the human cough with and without wearing masks for aerosol infection control. Journal of the Royal Society Interface, 6(suppl_6). https://doi.org/10.1098/rsif.2009.0295.focus

27. Topol, E. J. (2020). COVID-19 can affect the heart. Science, 370(6515), 408-409. https://doi.org/10.1126/science.abe2813

28. Van der Sande, M., Teunis, P., \& Sabel, R. (2008). Professional and home-made face masks reduce exposure to respiratory infections among the general population. PLoS ONE, 3(7), e2618. https://doi.org/10.1371/journal.pone.0002618

29. Van Green, T., \& Tyson, A. (2020, April 2). 5 facts about partisan reactions to covid-19 in the U.S. Pew Research Center. Retrieved August 19, 2021, from https://www.pewresearch.org/fact-tank/2020/04/02/5facts-about-partisan-reactions-to-covid-19-in-the-u-s/

30. Vitiello, A., La porta, R., D'aiuto, V., \& Ferrara, F. (2021). The risks of liver injury in covid-19 patients and pharmacological management to reduce or prevent the damage induced. Egyptian Liver Journal, 11(1). https://doi.org/10.1186/s43066-021-00082-y

31. Woodruff, J., Santhanam, L., \& Thoet, A. (2020, April 3). What Dr. Fauci wants you to know about face masks and staying home as virus spreads. PBS. Retrieved August 22, 2021, from https://www.pbs.org/newshour/show/what-dr-fauci-wants-you-to-know-about-face-masks-and-stayinghome-as-virus-spreads

32. Xu, R., Ekiert, D. C., Krause, J. C., Hai, R., Crowe, J. E., \& Wilson, I. A. (2010). Structural basis of preexisting immunity to the $2009 \mathrm{~h} 1 \mathrm{n} 1$ pandemic influenza virus. Science, 328(5976), 357-360. https://doi.org/10.1126/science. 1186430

33. Yaqinuddin, A. (2020). Cross-immunity between respiratory coronaviruses may limit covid-19 fatalities. Medical Hypotheses, 144, 110049. https://doi.org/10.1016/j.mehy.2020.110049

34. Yelin, I., Katz, R., Herzel, E., Berman-zilberstein, T., Ben-tov, A., Kuint, J., Gazit, S., Patalon, T., Chodick, G., \& Kishony, R. (2021). Associations of the bnt162b2 covid-19 vaccine effectiveness with patient age and comorbidities. Science. https://doi.org/10.1101/2021.03.16.21253686

35. Zhang, N.-N., Li, X.-F., Deng, Y.-Q., Zhao, H., Huang, Y.-J., Yang, G., Huang, W.-J., Gao, P., Zhou, C., Zhang, R.-R., Guo, Y., Sun, S.-H., Fan, H., Zu, S.-L., Chen, Q., He, Q., Cao, T.-S., Huang, X.-Y., Qiu, H.Y., . . Q Qin, C.-F. (2020). A thermostable mRNA vaccine against covid-19. Cell, 182(5), 1271-1283.e16. https://doi.org/10.1016/j.cell.2020.07.024 